\title{
A Miniature Microstrip Antenna Array using Circular Shaped Dumbbell for ISM Band Applications
}

\author{
Ahmed Ghaloua ${ }^{1}$, Jamal Zbitou ${ }^{2}$, Larbi El Abdellaoui ${ }^{3}$, Mohamed Latrach ${ }^{4}$, Ahmed Errkik ${ }^{5}$, \\ Abdelali Tajmouati ${ }^{6}$ \\ 1,2,3,5,6 LMEET Laboratory FST of Settat Hassan 1st University, Morocco \\ ${ }^{4}$ Microwave group ESEO Angers France, France
}

\section{Article Info}

Article history:

Received May 22, 2018

Revised Jul 22, 2018

Accepted Jul 29, 2018

Keyword:

CDGS

Circular shaped dumbbell

Ism band

Microstrip patch antenna

Printed antennas array

\begin{abstract}
The aim of this work is the achievement, and the validation of a small microstrip patch antenna array using a circular shaped dumbbell defected ground structure. This work has been dividing into two stages: The first step is to miniaturize a microstrip patch antenna resonating at $5.8 \mathrm{GHz}$, which operate in the Industrial Scientific Medical band (ISM) and the second is to use a circular defected ground structure to shift the resonance frequency of the antenna array from $5.8 \mathrm{GHz}$ to $2.45 \mathrm{GHz}$. At last, a miniaturization up to $74.47 \%$, relative to the original microstrip antenna array has accomplished. The antenna structure has designed, optimized and miniaturized using CST MW Studio. The obtained results have compared with Ansoft's HFSS electromagnetic solver. The antenna array has fabricated on FR-4 substrate, and its reflection coefficient is measured.
\end{abstract}

Copyright $(0) 2018$ Institute of Advanced Engineering and Science. All rights reserved.

\section{Corresponding Author:}

Ahmed Ghaloua,

Faculty of Sciences and Techniques,

University Hassan 1st,

University Complex Casablanca road, Km 3.5, B.P: 577 Settat, Morocco.

Email: ahmed.ghaloua@gmail.com

\section{INTRODUCTION}

Many research is devoted to improving the performances of microwave devices, especially of microstrip patch antenna. From the result of modern mobile communications systems and the rapid development in wireless communications, the microstrip patch antennas size reduction has become global research areas. To our knowledge, various methods have been recently proposing for miniaturizing geometric dimensions of microstrip patch antenna or antenna array. For instance using the defected microstrip structure (DMS) [1], defected ground structure (DGS) [2], magneto-dielectric substrate [3], antenna loaded with a very high permittivity substrate [4], antenna loaded with grounded strips [5], loading shorting pins or shorting walls [6], loading distributed capacitors and/or inductors [7] and composite right/left-handed (CRLH) metamaterial structures have also been applied to reduce the size of patch antennas [8].

Although the defected ground structure (DGS) has advantages in the area of the microwave filter design [9], microwave oscillators, microwave couplers and microwave amplifiers. It is also used in printed antenna design for different applications such as cross polarization suppression or reduction [10], [11], mutual coupling reduction [12], for compact size wireless power transfer applications [13], control of higher harmonics and their radiations [14] as well eliminate the scan blindness in a microstrip phased array design [15]. The defected ground structure is composed of two defected areas, and a connecting slot, few applications for DGSs in microstrip lines was reporting, among them are [16]: The dumbbell shaped DGS [17], [18], two-dimensional (2D) DGSs is proposed in [19], the dumbbell structure is added as a unit-cell in a systematic manner in both horizontal and vertical directions to construct the 2D-DGSs and a spiral shaped DGS [20]. What a defected for the microstrip line is an etching in the backside metallic ground plane. 
When the defected structure has introduced in a microstrip antenna, the defect geometry etched in the ground plane disturbs its current distribution and increases the effective inductance and capacitance of the microstrip line [16].

The proposed microstrip antenna array has miniaturized using a circular shaped dumbbell (CDGS) which had etched in the ground plane of each radiating element. The resonance frequency of the conventional structure of antenna array -without CDGS- has shifted from $5.8 \mathrm{GHz}$ to $2.45 \mathrm{GHz}$ after introducing the CDGS. The structure has a very compact geometry compared with a conventional microstrip antenna array resonating at $2.45 \mathrm{GHz}$.

\section{MICROSTRIP PATCH ANTENNA DESIGN}

The geometric dimensions of a uniform patch antenna, also known as microstrip antenna they calculated from the formulas given in [21]. For reducing the size of the conventional antenna, many shaped slots are introduced in the patch are demonstrated in the Figure 1. Consequently, the new antenna has a very compact geometry. In this design, the substrate FR-4 had used due to its low cost and easy fabrication. The substrate height is $1.6 \mathrm{~mm}$, the dielectric constant is 4.4 , and the loss tangent is 0.025 . After many series of optimization by using CST-MW solver, the final dimensions of the proposed antenna are giving in the Table 1. The simulated results indicate that the antenna has a good performance in term of matching input impedance $-17.06 \mathrm{~dB}$, gain $3.999 \mathrm{~dB}$, and the width frequency band is around $149.5 \mathrm{MHz}$ at $5.8 \mathrm{GHz}$.

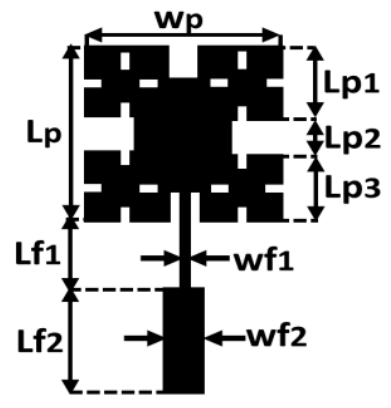

(a)

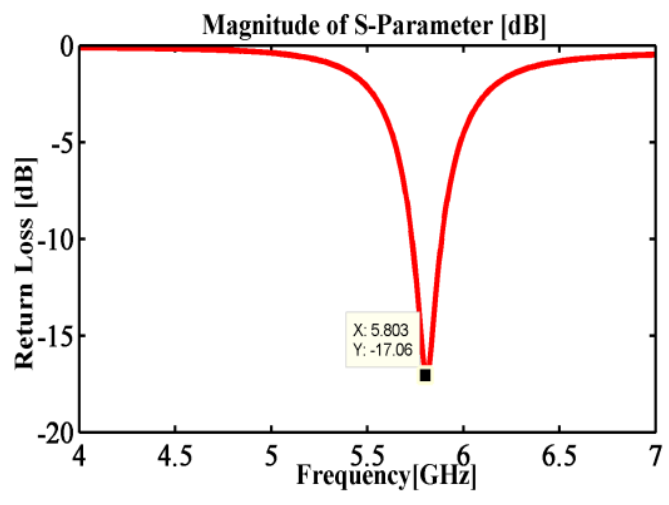

(b)

Figure 1. (a) Schematic diagram of microstrip antenna, (b) Simulated return loss of the microstrip patch antenna resonating at $5.8 \mathrm{GHz}$

Table 1. Dimensions of the Proposed Microstrip Patch Antenna

\begin{tabular}{cccc}
\hline Parameters & Value $[\mathrm{mm}]$ & Parameters & Value $[\mathrm{mm}]$ \\
\hline Lp & 10.4 & Lf2 & 5.0 \\
Lp1 & 4.6 & Wf1 & 0.475 \\
Lp2 & 1.6 & Wf2 & 3 \\
Lp3 & 4.2 & Wp & 10 \\
Lf1 & 3.9 & - & - \\
\hline
\end{tabular}

\section{PRINTED FOUR-ELEMENTS ANTENNA ARRAY}

Taking into account the antenna designed and described in the first section, we have designed an antenna array in order to increase the gain. The proposed antenna array had designed by using low cost FR-4 substrate $\left(170 \times 60 \mathrm{~mm}^{2}\right)$. The whole area of the radiating array is $147.64 \times 41.99 \mathrm{~mm}^{2}$. The dimensions are $\mathrm{L} 1=10.89 \mathrm{~mm}, \mathrm{~L} 2=14.85 \mathrm{~mm}, \mathrm{~L} 3=5.85 \mathrm{~mm}, \mathrm{w} 1=0.7 \mathrm{~mm}, \mathrm{w} 2=2.1 \mathrm{~mm}, w 3=3.0 \mathrm{~mm}, \mathrm{w} 4=0.7 \mathrm{~mm}, \mathrm{w} 5=1 \mathrm{~mm}$, $\mathrm{w} 6=3 \mathrm{~mm}, \mathrm{w} 7=0.475 \mathrm{~mm}$ and $\mathrm{d} 3=73.82 \mathrm{~mm}$. The structure of this antenna array as shown in Figure 2, It includes four patches with distances $\mathrm{d} 1=45.88 \mathrm{~mm}$ in one direction, adds to that the distance between the antennas edges has been selected to be $\mathrm{d} 2=35.88 \mathrm{~mm}\left(0.694 \lambda_{5.8 \mathrm{GHz}}\right)$, where $\lambda_{5.8 \mathrm{GHz}}$ is the free space wave length. The radiating elements are excited through simple corporate feed arrangement. This feed arrangement 
consists of matching transformer, quarter wave transformer $(\lambda / 4) \mathrm{T}$ power divider for better impedance matching between feed and radiating elements. The dimensions of the proposed antenna array had optimized by using CST Microwave Studio electromagnetic solver. The antenna array has a resonant frequency of $5.8 \mathrm{GHz}$, which covers ISM band applications, as shown in Figure 3.

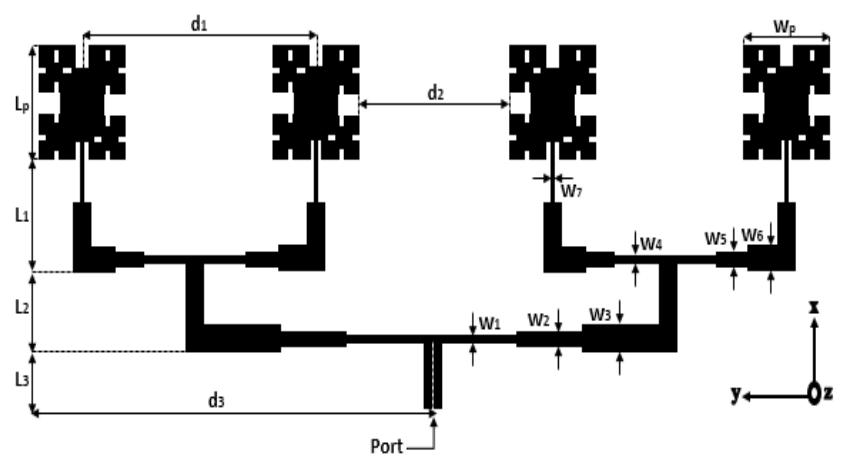

Figure 2. Top-view of the designed antenna array

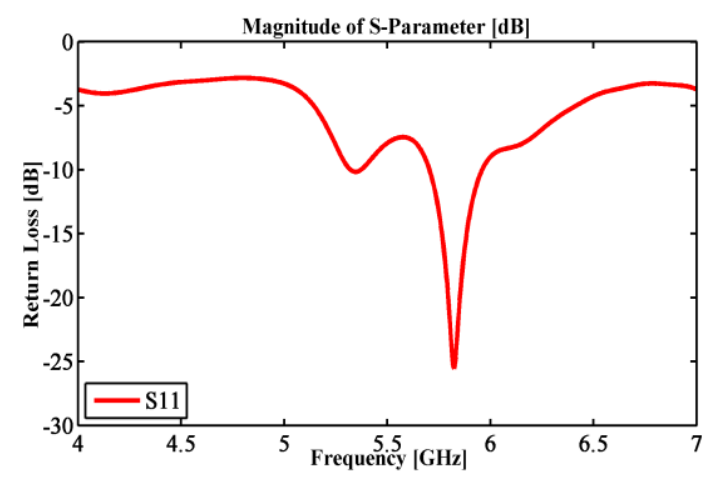

Figure 3. The simulated reflection coefficient versus frequency of the printed antenna array

\section{CIRCULAR SHAPED DUMBBELL (CDGS)}

The circular shaped dumbbell defected ground structure (CDGS) are composed of four circles defected areas: three circles linked to each other arranged on one side, and the singular circle in the other side of connecting slot etched between them, WDGS1xLDGS2 gaps and a narrow connecting slot wide etched areas in backside metallic ground plane as shown in Figure 4(a). The dimensions of the proposed circular defected ground structure are: LDGS1 $16.6 \mathrm{~mm}$, LDGS2 $=15.5 \mathrm{~mm}$, LDGS3 $=17.5 \mathrm{~mm}$, WDGS $1=1.1 \mathrm{~mm}$, WDGS2 $=15.2 \mathrm{~mm}, \mathrm{RDGS} 1=1.73 \mathrm{~mm}, \mathrm{RDGS} 2=1.7 \mathrm{~mm}, \mathrm{RDGS} 3=2.1 \mathrm{~mm}$ and RDGS4 $=1.73 \mathrm{~mm}$. The resonant frequency will have shifted by varying the dimensions of the circular shaped dumbbell. In general, the equivalent circuit of the CDGS consists of an inductance (L) and a capacitance (C) in parallel as seen in Figure 4(b) [22]. In addition, the values of these elements can be calculated by the formulas (1)-(3):

$$
\begin{aligned}
& X_{\mathrm{LC}}=\frac{1}{\omega_{0} c_{\mathrm{k} 1}\left(\frac{\omega_{0}}{\omega}-\frac{\omega}{\omega_{0}}\right)} \\
& X_{\mathrm{L}}=\omega^{\prime} \mathrm{z}_{0} \mathrm{~g}_{1} \\
& \left.\mathrm{X}_{\mathrm{LC}}\right|_{\omega=\omega_{\mathrm{c}, 3 \mathrm{~dB}}}=\left.\mathrm{X}_{\mathrm{L}}\right|_{\omega^{\prime}=1}
\end{aligned}
$$


where $\omega^{\prime}(=1), \mathrm{g} 1(=2)$ and $\mathrm{Z} 0(=50 \Omega)$ are normalized 3-dB cutoff frequency, element value of one-pole Butterworth prototype LPF, and port impedance, respectively, and: $\omega_{0}=\left(\mathrm{L}_{\mathrm{k} 1} \mathrm{C}_{\mathrm{k} 1}\right)^{-1 / 2}$.
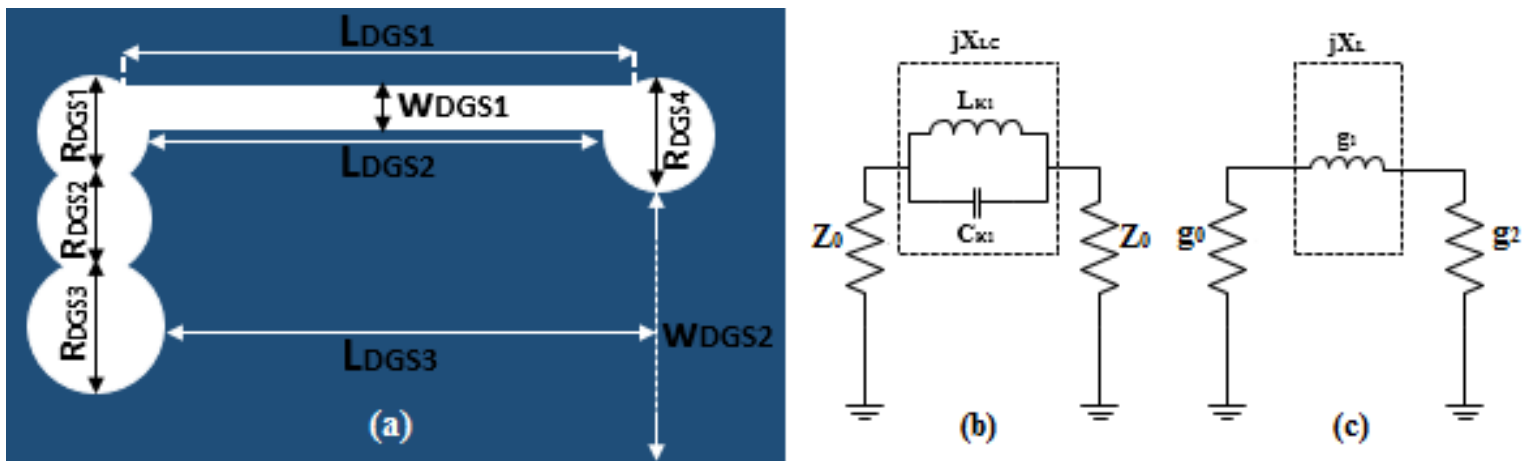

Figure 4. (a) CDGS unit: Circular shaped dumbbell unit, (b) Equivalent circuit of the microstrip line with unit CDGS, (c) Butterworth prototype of one-pole LPF [18]

\section{MICROSTRIP ANTENNA ARRAY WITH CDGS}

The ground plan of the antenna array has defected by using a circular shaped dumbbell presented in Figure 4(a) to shift the resonance frequency from $5.8 \mathrm{GHz}$ to $2.45 \mathrm{GHz}$ without changing the geometric dimensions of the original structure of antenna array. As can be seen, the resonant frequency has been significantly influenced by the CDGS. Namely, it brought to about $2.45 \mathrm{GHz}$. To validate this antenna structure we have used two electromagnetic solvers CST-MWS and HFSS, which permit to have a good agreement between both simulation results. It had observed that the resonant frequency had shifted from $5.8 \mathrm{GHz}$ to $2.45 \mathrm{GHz}$, with a return loss of $-19.98 \mathrm{~dB}$ at $2.45 \mathrm{GHz}$ and impedance bandwidth of $149.3 \mathrm{MHz}$ $(2380.8 \mathrm{MHz}-2530.1 \mathrm{MHz})$ which covers the operating frequency of the Industrial Scientific Medical (ISM) band. Moreover, the simulated gain at $2.45 \mathrm{GHz}$ is $7.60 \mathrm{~dB}$. We can conclude that the use of defected ground structure permits to reduce the surface occupied by the original antenna. Finally, a size comparison between our microstrip antenna array and the conventional one resonating at $2.45 \mathrm{GHz}$, show that the size of the conventional antenna array is almost three times larger than that of the microstrip antenna array with CDGS cells. As shown in Figure 5 and Figure 6.

Figure 7 shows the simulated gain versus frequency of the proposed antenna array. As observed, we have a maximum of gain around $7.24 \mathrm{~dB}$ at $2.45 \mathrm{GHz}$ and a decreasing of gain outside the bandwidth $(2380.8 \mathrm{MHz}-2530.1 \mathrm{MHz})$. For the behavior of the antenna array in term of radiation, we can analyze the radiation pattern of the array as depicted in Figure 8. We have seen that the antenna array is bidirectional. For current density, Figure 9 shows that the density of the current was more concentrated along the $\mathrm{T}$-junctions power dividers to feed the fourth antennas as well as along the CDGS on the ground plane.

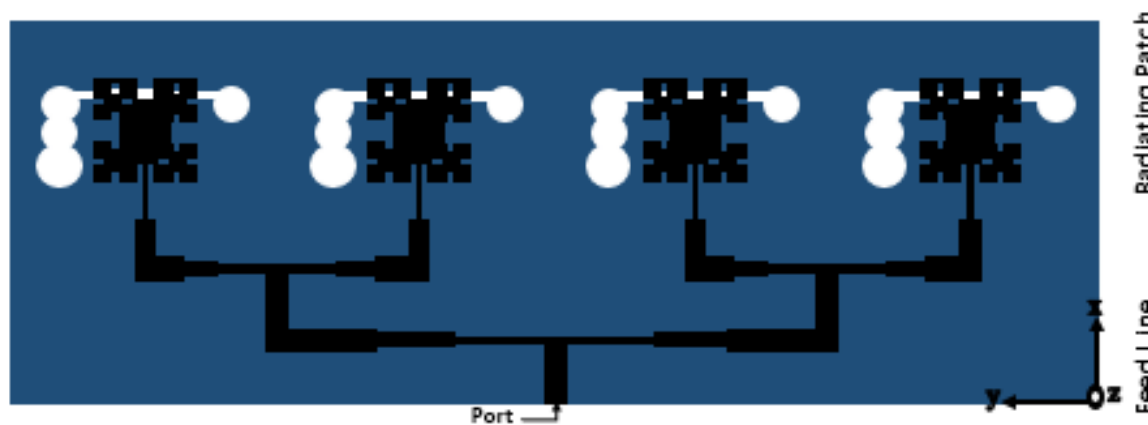

(a)

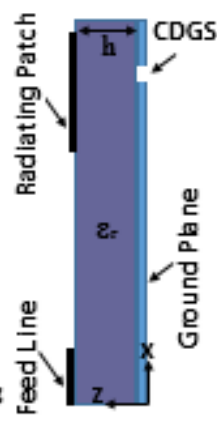

(b)

Figure 5. Printed antenna array with circular defected ground structure (CDGS) (a) view from the ground plane side, (b) side view 


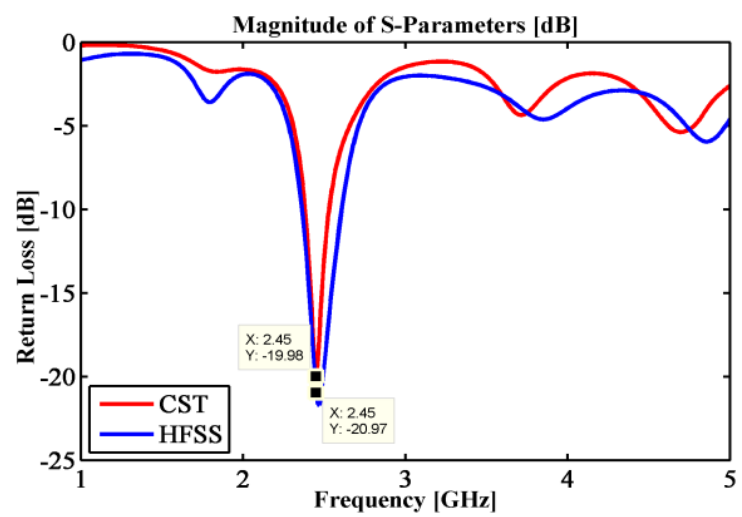

Figure 6. CST and HFSS reflection coefficient comparison of the designed antenna array with CDGS

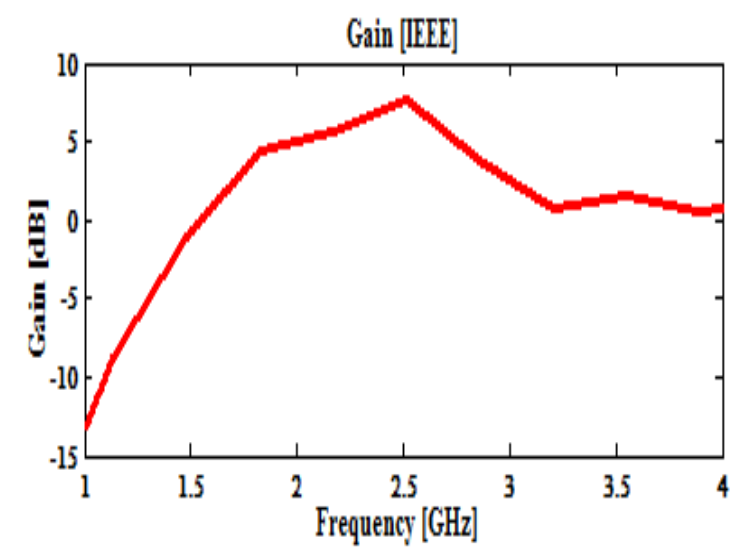

Figure 7. Gain Vs frequency of the proposed antenna array with CDGS

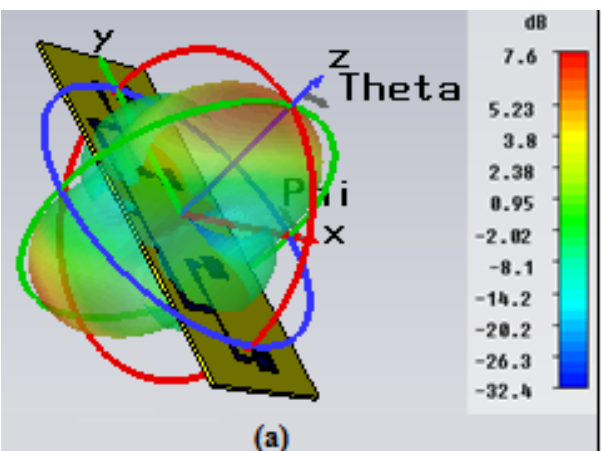

(a)

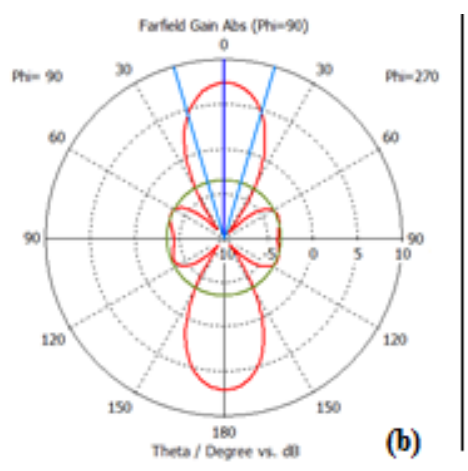

(b)

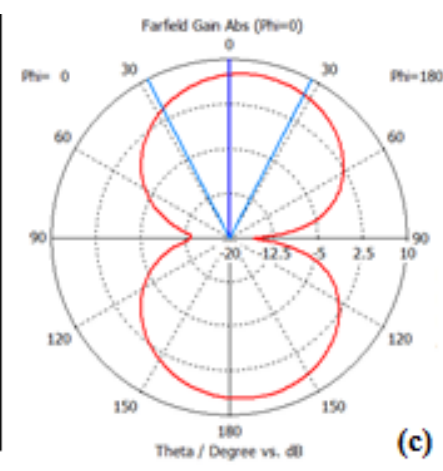

(c)

Figure 8. Radiation pattern of the proposed antenna array at $2.45 \mathrm{GHz}$ : (a) Three dimensional, (b) $\mathrm{Phi}=90^{\circ}$, (c) $\mathrm{Phi}=0^{\circ}$

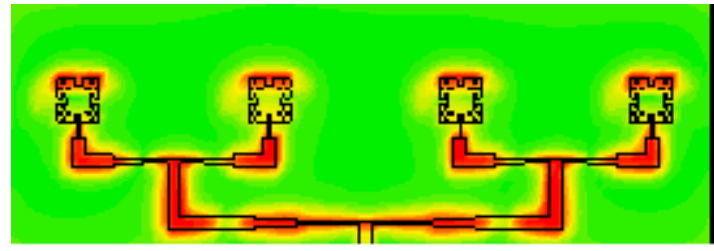

(a)

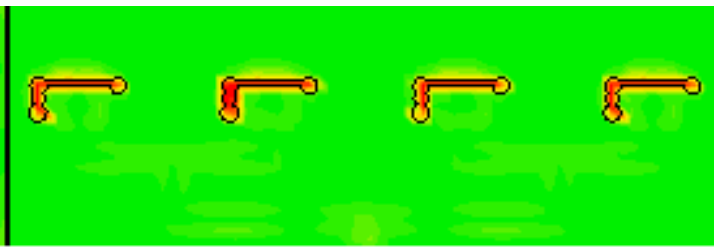

(b)

Figure 9. The current density of the antenna array with CDGS at $2.45 \mathrm{GHz}$, (a) front view, (b) back view 


\section{EXPERIMENTAL RESULTS AND DISCUSSION}

After consideration of all simulated results, we had chosen to realize the prototype of the proposed antenna array structure by using the LPKF machine, in order to check the performance of the simulation results of the reflection coefficient. The circuit had printed on the FR-4 substrate. Figure 10 shows the picture of the novel fabricated structure of the antenna array with the circular shaped dumbbell defected ground structure. The antenna array is compact, miniature, low cost and it has a total area of $170 \times 60 \mathrm{~mm}^{2}$. After testing the achieved antenna array, we have conducted a comparison between simulation by CST-MWS and measurement results as shown in Figure 11.

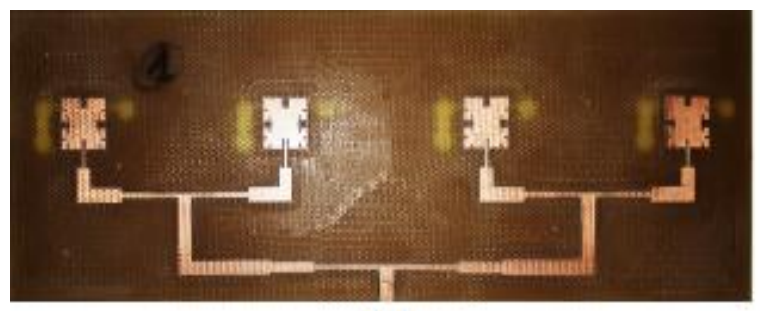

(a)

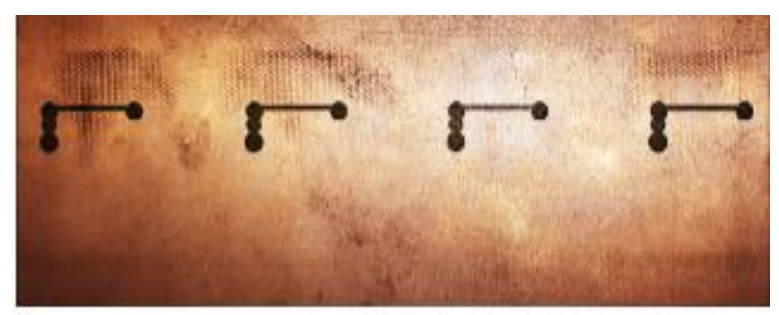

(b)

Figure 10. Fabricated antenna array with CDGS, (a) front view, (b) back view

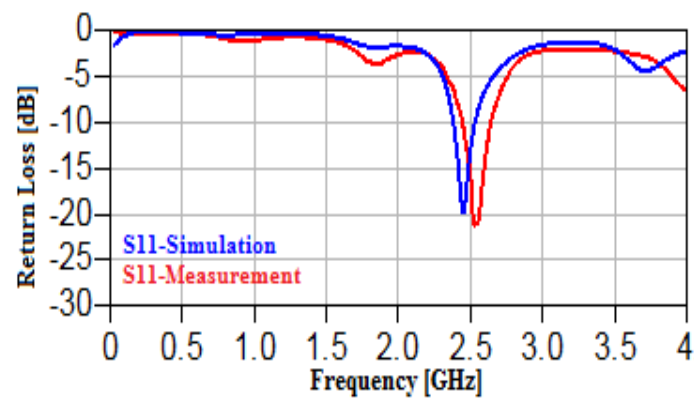

Figure 11. Comparison between the simulated and the measured results of the proposed antenna array

Table 2. A Synthesis of the different Results Obtained by Simulation and Measurement

\begin{tabular}{lccl}
\hline \multicolumn{1}{c}{ Parameters } & Frequency [GHz] & Return loss [dB] & Bandwidth [MHz] \\
\hline Simulated Results by CST-mws & 2.45 & -19.97 & $2380.8-2530.1$ \\
Simulated Results by HFSS & 2.47 & -21.71 & $2365.0-2605.0$ \\
Measured Results & 2.52 & -21.23 & $2440.0-2640.0$ \\
\hline
\end{tabular}

\section{CONCLUSION}

In this study, a novel design of antenna array with a circular shaped dumbbell had developed and validated. This antenna array had designed and optimized by using CST-MWS and HFSS electromagnetic solvers. The structure with and without defected ground structure are presented and detailed. The achieved and tested printed antenna array with CDGS presents a good agreement between simulation and measurement results. These results validate the antenna array structure at $2.45 \mathrm{GHz}$, which operate in the Industrial Scientific Medical band (ISM).

\section{ACKNOWLEDGEMENTS}

We thank Mr. Mohamed Latrach Professor in ESEO, engineering institute in Angers, France, for allowing us to use all the equipments and solvers available in his laboratory. 


\section{REFERENCES}

[1] P. Kumar, et al., "Formulation of Size Reduction Technique in Microstrip Circuits by using DGS and DMS", 2008 International Conference on Recent Advances in Microwave Theory and Applications, Jaipur, 2008, pp. 861-864.

[2] M. U. Khan, et al., "Microstrip patch antenna miniaturisation techniques: a review", in IET Microwaves, Antennas \& Propagation, vol. 9, no. 9, pp. 913-922, 2015.

[3] F. Farzami, et al., "Miniaturization of a Microstrip Antenna Using a Compact and Thin Magneto-Dielectric Substrate", in IEEE Antennas and Wireless Propagation Letters, vol. 10, pp. 1540-1542, 2011.

[4] Y. Hwang, et al., "Planar Inverted F Antenna Loaded with High Permittivity Material", in Electronics Letters, vol. 31, no. 20, pp. 1710-1712, 28 Sep 1995.

[5] M. Yang, et al., "Miniaturized Patch Antenna With Grounded Strips", in IEEE Transactions on Antennas and Propagation, vol. 63, no. 2, pp. 843-848, Feb. 2015.

[6] Wong, Kin-Lu, Compact and Broadband Microstrip Antennas, John Wiley \& Sons, 2004.

[7] C. Y. Chiu, et al., "A Tunable Via-Patch Loaded PIFA With Size Reduction”, in IEEE Transactions on Antennas and Propagation, vol. 55, no. 1, pp. 65-71, Jan. 2007.

[8] P.K. Singhal and Bimal Garg, "Design and Characterization of Compact Microstrip Patch Antenna Using "Split Ring” Shaped Metamaterial Structure", International Journal of Electrical and Computer Engineering (IJECE), vol. 2, no. 5, pp. 655-662, October 2012.

[9] A. Boutejdar, et al., "Design and Improvement of a Compact Bandpass Filter using DGS Technique for WLAN and WiMAX Applications", TELKOMNIKA (Telecommunication, Computing, Electronics and Control), vol. 15, no. 3, pp. 1137-1144, September 2017.

[10] C. Kumar and D. Guha, "Nature of Cross-Polarized Radiations from Probe-Fed Circular Microstrip Antennas and Their Suppression Using Different Geometries of Defected Ground Structure (DGS)", in IEEE Transactions on Antennas and Propagation, vol. 60, no. 1, pp. 92-101, Jan. 2012.

[11] D. Guha, et al., "Microstrip Patch Antenna with Defected Ground Structure for Cross Polarization Suppression", in IEEE Antennas and Wireless Propagation Letters, vol. 4, no. 1, pp. 455-458, 2005.

[12] F. G. Zhu, et al., "Reduction of Mutual Coupling between Closely-packed Antenna Elements using Defected Ground Structure", in Electronics Letters, vol. 45, no. 12, pp. 601-602, June 42009.

[13] S. Hekal, et al., "A Novel Technique for Compact Size Wireless Power Transfer Applications Using Defected Ground Structures", in IEEE Transactions on Microwave Theory and Techniques, vol. 65, no. 2, pp. 591-599, Feb. 2017.

[14] S. Biswas, et al., "Control of Higher Harmonics and Their Radiations in Microstrip Antennas Using Compact Defected Ground Structures", in IEEE Transactions on Antennas and Propagation, vol. 61, no. 6, pp. 3349-3353, June 2013.

[15] D. b. Hou, et al., "Elimination of Scan Blindness with Compact Defected Ground Structures in Microstrip Phased Array", in IET Microwaves, Antennas \& Propagation, vol. 3, no. 2, pp. 269-275, March 2009.

[16] A. Ortega, et al., "Design of Low-pass Microstrip Filters based on Defected Ground Structure", 2011 SBMO/IEEE MTT-S International Microwave and Optoelectronics Conference (IMOC 2011), Natal, 2011, pp. 69-74.

[17] Liu, et al., "A New Parameter-Extraction Method for DGS and its Application to the Low-Pass Filter", Active and Passive Electronic Components, 2004, vol. 27, no. 2, pp. 119-123.

[18] D. Ahn, et al., "A Design of the Low-Pass Filter using the Novel Microstrip Defected Ground Structure", in IEEE Transactions on Microwave Theory and Techniques, vol. 49, no. 1, pp. 86-93, Jan 2001.

[19] C. Shekhar, et al., "Application of 2D Defected Ground Structures in Microstrip Lines", 2013 IEEE International Conference on Electronics, Computing and Communication Technologies, Bangalore, 2013, pp. 1-4.

[20] Chul-Soo Kim, et al., "Equivalent Circuit Modelling of Spiral Defected Ground Structure for Microstrip Line", in Electronics Letters, vol. 38, no. 19, pp. 1109-1110, 12 Sep 2002.

[21] Low Ching Yu and Muhammad Ramlee Kamarudin, "5G Fixed Beam Switching on Microstrip Patch Antenna”, International Journal of Electrical and Computer Engineering (IJECE), vol. 7, no 2, p. 975-980, April 2017.

[22] Jong-Sik Lim, et al., "Design of Low-Pass Filters using Defected Ground Structure", in IEEE Transactions on Microwave Theory and Techniques, vol. 53, no. 8, pp. 2539-2545, Aug. 2005.

\section{BIOGRAPHIES OF AUTHORS}

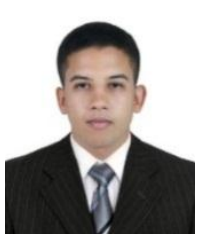

Ahmed Ghaloua was born in Kasbat Tadla, Morocco, In July 1990. He received the master degree in electronics and telecommunications from Faculty of Sciences, University of Abdelmalek Essaidi Tetouan, Morocco. He is currently working toward the Ph.D. degree in physics and engineering sciences at Faculty of Sciences and Technologies, Settat, Morocco. His research interests include the analysis and design of antenna arrays using Metamaterials structures. 


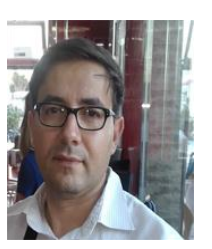

Jamal Zbitou was born in Fes, Morocco, in June 1976. He received the Ph.D. degree in electronics from Polytech of Nantes, the University of Nantes, Nantes, France, in 2005. He is currently an associate Professor of Electronics in FST, University Hassan 1st, Settat, Morocco and the head of Computing Networks and telecommunication in LMEET Laboratory in FSTS. He is involved in the design of hybrid, monolithic active and passive microwave electronic circuits.

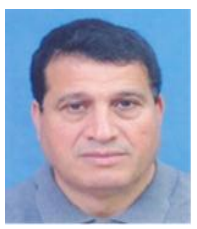

Larbi El Abdellaoui was born in Tiflet, Morocco, in 1961. He received the Ph.D. degree in electronics from the University of Metz, in 1994, France. He is currently an associate Professor of Electronics in Faculty of sciences and techniques, University Hassan 1st, Settat, Morocco. He is involved in the design of hybrid, monolithic active and passive microwave electronic circuits.

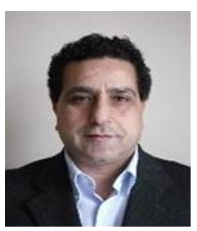

Mohamed Latrach (IEEE member) received the Ph.D. degree in electronics from the University of Limoges, Limoges, France, in 1990. He is currently Professor of microwave engineering with the Ecole Supérieure d'Electronique de l'Ouest (ESEO), Angers, France, where he is head of the RadioFrequency \& Microwave research group. His research interests include: design of hybrid \& monolithic active and passive microwave circuits, metamaterials, LH materials, antennas, rectennas and their applications in wireless communications, and wireless power transmission (WPT).

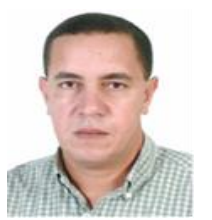

Ahmed Errkik was born in July 1960 in Morocco. He received the Ph.D. degree in physics from the University of Technology Compie'gne (UTC), Compie'gne, France. He is currently an associate Professor of physics in FST University Hassan 1st, Settat, Morocco. He is involved in the design of hybrid, monolithic active and passive microwave electronic circuits.

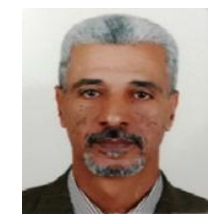

Abdelali Tajmouati was born in, Morocco, in 1962. He received the Ph.D. degree in science engineering from the University of Perpignan, France, in 1992. He is currently an associate Professor of Electronics, thermal transfer and thermodynamic in Faculty of sciences and techniques University Hassan 1st, Settat, Morocco. He is involved in the design of hybrid, monolithic active and passive microwave electronic circuits. 